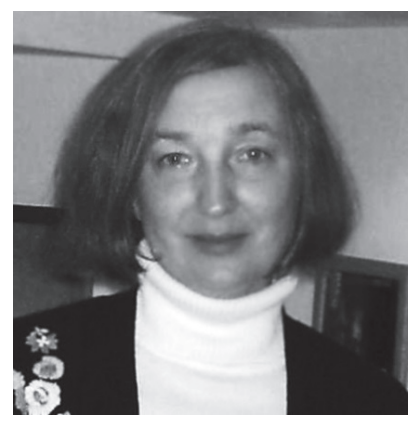

Jelena Barnašova - filologijos mokslų kandidatè, Kultūros teorijos ir istorijos katedros docenté, Menų ir kultūros institutas, Nacionalinis tiriamasis Tomsko valstybinis universitetas.

Moksliniai interesai: literatūros ir kultūros istorija, natūralizmo problemos literatūroje, mimezio problemos mene.

Adresas: 634012, Россия, г. Томск, ул. Киевская, 86 «б», кв. 54. El.paštas: bev0203@gmail.com.

Elena Barnashova: Candidate of pfilological sciences, The associate Professor of Department of theory and history of culture, Institute of arts and culture, National Research Tomsk State University. Research interests: history of literature and culture, problems of naturalism in literature, problems of mimesis in art.

Adress: Kievskaya street 86 "b" - 54, 634012 Tomsk, Russia.

E-mail: bev0203@gmail.com.

\title{
Елена Барнашова
}

Томский университет

\section{ОППО ЗИЦИЯ «ВОДА- 3 ЕМЛЯ» В ЭВОЛЮЦИИ ХУДОЖЕСТВЕННОЙ КУЛЬТУРЫ ХІХ ВЕКА}

\section{Anotacija}

Su vandeniu susiję archetipai yra gerai žinomi nuo seniausių laikų. XIX a., pasižyminčiame racionalizmo krizėmis, aktualizuojamas archetipas vanduo kaip iracionalumo požymis. Antitezė „racionalus-iracionalus“ literatūroje ir mene nusakoma žemès ir vandens priešprieša. Ši dvinare opozicija matyti žymiausių romantizmo ir realizmo menininkų darbuose. Vandens, ypač jūros, ịvaizdžiai būdingi romantizmui, padeda realizuoti jo pagrindines menines ir estetines idejas. Iracionalioji stichija, tai, kas nenusakoma, vaizduojama šèlstančia jūra, dramatizmas ir likimo vingiai - paveiksluose, vaizduojančiuose laivo sudužimą. Jūra - begalinè, bekraštė erdvè, laikas, visuma (Dž. Baironas, U. Terneris, T. Žeriko, K. Fridrichas ir kt.).

İsigalint realizmo, vèliau natūralizmo, epochai, kurios interesas - žmogaus socialinė padètis, ,,vanduo pasitraukia“, užleisdamas vietą sausumai, žemei. Vaizdų sistemoje, veikiant materialistinèms tendencijoms ir pozityviajam mokslo žinių kultui, dominuoja stabilumas, žinios, tikrumas. Žemé materijos, gamtos centras (E. Zolia „Žeme““). Jei kūryboje vaizduojamas vanduo, audringas jūros bangas keičia rami upès tékmė (Barbizono mokyklos dailininkai).

PAGRINIDINIAI ŽODŽIAI: archetipai, kultūros procesai, XIX amžius, iracionalumas ir racionalumas, vandens ir žemès įvaizdžiai.

\begin{abstract}
Well known established over many centuries and wandering in the culture of the archetypes associated with water. In the nineteenth century, which marked crisis of rationalism, we can distinguish archetype: water as the embodiment irrational. Accordingly, the antithesis of "rational-irrational" appears in literature and art through the contrast of images of earth and water. This binary reveals itself in the evolution of the leading art schools of romanticism and realism. Water, especially the sea, images prevail in romanticism, allow to realize its leading artistic and aesthetic ideas. Irrational element, the unpredictability embodied in the images of a stormy sea, the drama and the wrong-
\end{abstract}


ness of fate - in the pictures of the shipwreck. Sea - infinity, the vastness of space, time, existence in General (J. Byron, U. Turner, T. Gericault, K. Friedrich, and others). In the era of establishing realistic, and then naturalism, with their interest in social existence of man, "water recedes", giving place to land, the earth. In the image system, under the influence of materialistic tendencies and positivist cult of scientific knowledge, is dominated by the resistance, finiteness, definiteness. The earth is the center of matter, nature (E. Zola "Earth"). If the field of view of water falls, lush shimmering sea gives way to the calm water surface ("Barbizon painters").

KEY WORDS: archetypes, the processes in the culture of the XIX century, irrational-rational, images of water, images of the earth.

DOI: http://dx.doi.org/10.15181/rh.v18i0.1227

В в е де ни е

Хорошо известны сложившиеся за долгие века и блуждающие в культуре архетипы, связанные с водой. Вода-очищение, вода как опасная стихия (морская буря, потоп), вода поглощающая - «мертвая вода», вода возрождающая - «живая вода» («вода-жизнь»). Текущая вода - «река жизни», символ истекающего времени, ускользания, неуловимости. Море - бескрайность пространства, времени, бытия в целом. Вода как символ прозрачности (стекло), но может быть и воплощением замутненности, размытости (искажающая призма), таинственности (скрытых глубин).

Многие из этих архетипических значений воды, начиная с древних мифов, фольклора, закрепились как универсальные, вневременные. Глубоко укорененные в культуре, они могут обнаруживаться в разные исторические периоды. Однако в каждую конкретную эпоху актуализируются в большей мере те или иные из этих значений, отражая глубинные интенции культуры. B XIX столетии, которое отмечено болезненными и взрывными кризисами рационализма, можно выделить архетип: вода как воплощение иррационального, стихийного - и в этом качестве она противопоставлена земле как воплощению рационального, упорядоченного. Это достаточно древняя оппозиция в культуре. Она проступает, например, еще в античной мифологии. Противопоставление воды-земли как отражение антитезы иррационального-рационального наметилось уже в космогоническом мифе о переходе из первоначального Хаоса, который ассоциировался со стихией мирового океана, в Космос - упорядоченный мир, причем, началом кристаллизации космоса было рождение Геи-земли. Это противостояние отразилось и в мифах о территориальных спорах богов, в которых над Посейдоном, воплощавшим стихию морского хаоса, одерживали победу боги, отвечавшие за плодородие земли, рождение городов, утверждение упорядоченного мирового порядка и разумного общественного уклада. Речь, конечно, идет об Олимпийском, т.е. довольно позднем, цикле мифов, когда, на стадиях 
позднеродового и раннеклассового обществ, стало обозначаться утверждение разумного, человеческого начала в природе, т.е. отслоение культуры от природы. Например, спор Посейдона с Афиной за город, который потом назовут Афинами в честь победившей богини. Ее подарок - оливковое дерево - оказался более ценным, чем подаренный богом морей источник, что отражает приоритеты эпохи утверждения земледелия, городов, формирования цивилизаций, рационального знания. Те же приоритеты определили проигрыш Посейдона в спорах с Зевсом за Эгину, с Герой за Арголиду, с Дионисом за Коринф. Земля и земные дела людей, как разумных существ, становятся важнее водной стихии.

Подспудно существуя в культурной памяти, антитеза воды-земли как «иррационального-рационального» актуализируется в культуре Нового времени и обретает особую остроту в XIX веке. Здесь выстраивается особый сюжет. Культура этого столетия отличается стремительной динамикой развития, быстрой сменой мировоззренческих позиций и художественных систем. В этом плане представляется интересным рассмотреть диалектику протекающих культурных процессов эпохи через развитие оппозиции «иррациональное-рациональное». Цель данного исследования: проследить, как эта оппозиция проявляется в литературе и искусстве через противоположность семантической наполненности образов воды и земли. Не касаясь всех вариантов проявления данной бинарности, обратим внимание на то, как она обнаруживает себя в эволюции ведущих художественных направлений эпохи - романтизма и реализма.

\section{Образы воды в романтизме}

«Водные» образы относились к числу излюбленных в романтизме, позволяли реализовать его ведущие художественно-эстетические интенции. Иррациональная стихия, мощь природы, не охватываемая разумом, воплощались в очень распространенных образах бушующего моря. Путешествие по морю - это безграничные возможности новой жизни, приключений, впечатлений, изменений в своей судьбе, в сложившемся жизненном укладе. Об этом повествуют многочисленные морские романы приключений о скитальцах, конкистадорах, «открывателях новых земель». Это и яркие байроновские герои - Чайльд Гарольд, Корсар, Дон-Жуан, - и персонажи морских романов Э. Сю. Линия достаточно жизнестойкая в литературе, и, отражая неоромантические тенденции, протягивается через все столетие вплоть до романов Р. Стивенсона, Дж. Р. Киплинга, Ж. Верна.

Превратность судьбы, непредсказуемость, иррациональность человеческого бытия отражались в часто повторяющемся сюжете: попавшее в бурю, 
мечущееся среди волн судно (лодка, корабль, плот). В этом ряду - сцены кораблекрушения Дон-Жуана у Байрона, драматические морские пейзажи У. Тернера, «Плот «Медузы» (1819) Т. Жерико, в котором историк Ж. Мишле увидел саму Францию в исторических бурях. Это и навеянное произведением Байрона «Кораблекрушение Дон-Жуана» у Э. Делакруа. Собственно, даже первая представленная публике картина Делакруа «Ладья Данте»- из той же серии, хотя изображено не море, а подземная река в одном из кругов ада, но река бурлит, хотя не волнами, а вздымающимися фигурами грешников. Это плавание так же опасно, как по бушующему морю, здесь та же коллизия, героям тоже приходится пробираться сквозь опасную напряженную стихию, в данном случае, стихию человеческих страстей страдания, страха, мольбы.

Мотив одиночества проступал в образе затерянного в морском просторе «одинокого паруса» (М. Лермонтов). Ощущение бесконечности, неохватности бытия передавалось через образ водного (чаще - морского) простора, открывающегося с берега. Этот мотив часто разрабатывался в творчестве немецких художников-романтиков дюссельдорфской школы (Ганс Гуде, Эжен Дюкер и др.). Но особенно ярко и пронзительно представлен в работах К. Д. Фридриха. Берег (пологий или утес) - это край земли, встреча суши и воды, устойчивого и зыбкого, конечного и бесконечного, рационального и иррационального, знакомого и неизведанного. Романтики в своих произведениях часто варьируют ситуацию: человек на грани между миром социальным и свободной природной стихией, куда устремляются взоры и автора, и героя. Это закрепляется в устойчивых композиционных моделях, сюжетных мотивах, позициях. Романтический герой часто всматривается вдаль, стоя на берегу моря, восхищается иррациональной игрой бушующих волн, безграничностью пространства. В этом смысле один из его самых характерных морских пейзажей - «Монах на берегу моря» (1810) К. Фридриха. Маленькая человеческая фигура изображена спиной к зрителю, такая постановка присутствует во многих картинах Фридриха, акцент переносится на масштабность морской стихии, подчеркивается приоритет природы над человеком, ее подавляющее и восхищающее величие. Подчас человек на картинах художника только стаффаж, иногда он вообще исчезает из пейзажа. Природа настолько одухотворена и наполнена чувством, что становится самодостаточной в эмоциональном выражении. Любимый романтиками жанр пейзажа - это, как правило, пейзаж человеческой души.

Морские образы вписывались в общую концепцию природы в романтизме - как воплощения свободы, иррациональной, вольной стихии, не скованной жесткими рамками и находящейся в постоянном движении и 
развитии, как воплощения бесконечности и красоты. Природа противостоит застывшей, устаревшей, рационалистически нормативной культуре классицизма, сковывающей свободу (и, прежде всего, свободу творчества). Таким образом, антитеза воды-земли по-своему отражала актуальную для эпохи проблему соотношения природного и культурного (человеческого, социального). В этом смысле романтической концепции в наибольшей степени отвечали именно водные морские образы. Что не исключает и образов земных, но воплощающих все ту же идею величия, свободы, безграничности природы (ее бурное цветение весной, густо разросшиеся, таинственные дикие леса, нагромождение мощных гор, грозно собирающиеся тучи), т.е., природа представала в стихийном, несколько взволнованном (от слова волна) экзальтированном состоянии, подобном встревоженному состоянию романтической души.

Очевидны коннотации между образами природы в немецкой романтической живописи и концепцией природы в эстетике романтиков-литераторов «иенской школы» (братья Шлегели, Л. Тик, Новалис). Многие ее положения эксплицированы в натурфилософии Ф. Шеллинга, близкого «иенцам». Главная идея - бесконечная производительная, творческая сила, заложенная в природе, неустанное и непрерывное жизнетворчество. Сложившая иерархия между культурным и природным, долгие века утверждавшая приоритет первого и потребительское отношение Homo sapiens к природе, стала переосмысляться уже в натурфилософии предромантической эпохи, в сочинениях И. Гете, К. Каруса. Границы между природным и культурным (человеческим) начинают смещаться, размываться. В шеллингианской концепции, так же, как в воззрениях Новалиса («Фрагменты», «Ученики в Саисе»), природа не только уравнивается в правах, но возносится над мелочной суетой, над ограниченностью и скованностью человеческого бытия. В натурфилософии, как и в эстетике романтизма, природа одухотворяется.

По Шеллингу, природа это зримый дух. «Наивысшей степенью совершенства естествознания было бы полное одухотворение всех законов природы, которое превратило бы их в законы созерцания и мышления» (Шеллинг 1987, 233). Мир един, постижение его в его целостности возможно за пределами рационального «наукоучения» и наиболее осуществимо в художественно-образном осмыслении и отражении. Преодолевая ограниченность и скованность культуры, человек пытается выйти из сферы социокультурного воздействия и обращается к природе, стремится примкнуть к ней, раствориться. Это растворение не в материалистическом смысле - как распадение на атомы и слияние с материей, но слияние с Мировой душой, 
которая разлита (сокрыта) в иррациональной природной стихии, первозданном Хаосе, мироздании, бесконечности.

Новалис, пережив, как и Шеллинг, увлечение «наукоучением» Фихте и отойдя потом от его идеалистической отвлеченности, создал свою натурфилософию, чем-то перекликающуюся с идеями о природе Шеллинга. Он понимает природу, как чувственную и, в то же время, одухотворенную стихию. Понимая природу в духе древнего анимизма, Новалис предлагал видеть населяющие ее дриады и ореады. Такое пантеистическое примирение романтического идеализма с материальной природой объясняет, казалось бы, парадоксальный факт - увлечение романтиков естественными науками (Новалис, А. Шамиссо). В этом они следуют за Гете. Идея одухотворенной природы на новом уровне повторяет древний миф. Мифотворчество близко романтикам, поскольку миф представляет духовный континуум, концентрированное обобщение, им важна «гиперболическая обобщенность» мифа, которую должна унаследовать поэзия. На этом настаивает Ф. Шлегель в «Речи о мифологии»: «Мифология и поэзия едины и неразрывны» (Литературные манифесты западноевропейских романтиков 1980, 63). Шеллинг в курсе лекций «Введение в философию мифологии» развивает ту же мысль: «...поэзия могла послужить естественным концом мифологии» (Шеллинг 1989, 175).

В плане противостояния рационального-иррационального важно также присущее романтикам разрушение (непризнание) границ. В художественных маринах безграничность моря и стремление человека слиться с этой стихией отражается в размывании и даже отсутствии четкой линии горизонта, когда сливаются два пространства - моря и неба. Разрушению границ способствуют подвижность, неустойчивость воды, и особенно безбрежность и непредсказуемость моря. Вновь актуализируется идея Хаоса. По замечанию $\Phi$. Шлегеля, «Хаос есть та запутанность, из которой может возникнуть мир» (Берковский 2001, 24). Он называет его «плодоносящий хаос» и понимает в шеллингианском духе - как творческую и всерождающую жизненную стихию. Хаос - это и романтическая безбрежность, и творчество, и безграничные возможности, и великая тайна, и продуктивная неоформленность мира.

Эти деструктивные с точки зрения классицистического искусства (академической традиции), иррационалистические художественно-эстетические тенденции ярко проявились в творчестве английского живописца Джозефа Уильяма Тёрнера. Его марины поражают смешением форм, красок, линий, размыванием границ между верхом и низом, небом и морем. Изображение морского шторма часто строится по принципу круговой композиции, когда 
все стихии - ветер, грозные тучи, волны, рвущиеся их морских глубин, взлетающие выше кораблей и поглощающие их - сливаются в один клубок. Здесь трудно четко различить отдельные предметы, нет их строгой рациональной очерченности. Нет и материальной весомости, что придает его образам бесплотность и воздушность. Размыты все границы в картине Тёрнера «Утро после потопа», где очевидны ассоциации с первозданным Хаосом.

Английские романтики также не отказывали природе в ее правах, признавали существование материи. Сказывалось влияние английского сенсуализма, в частности, Д. Хартли («Наблюдения над человеком», 1749), которое было значительным у романтиков «озерной школы»- У. Вордсворта, С. Кольриджа. Они развивали и теорию ассоциаций в познании, которая предполагала тесную связь природного мира и его духовного осмысления человеком. Искусство воплощает в себе единство материального и духовного, природы и человека. В понимании единства бытия проступает пантеистическая идея растворенного в мире Божественного начала, мировой Души. Постичь это единство способно человеческое сознание, а отразить (схватить $)$ - континуум художественного образа.

Кольридж размышляет об особенностях художественного отражения. Развивая распространенное в XVIII веке понятие «подражание», он придает ему новый смысл. Уточняет, что подражание не значит копирование. «Если художник копирует внешние черты природы (natura naturata), какое это напрасное соперничество! ... Поверьте мне, вам следует совершенствоваться в изображении сути (natura naturans), а это предполагает соответствие природы и души человека» (Кольридж 1987).

Подражание - не копии предметов, не сводится к изображению внешних форм бытия. Иначе оно подобно созданию восковых фигур, которые чаще неприятны людям своей мертвенностью и бессмысленны. Для художника важны фантазия и воображение, переосмысление предметов. В этом плане характерна полемика Кольриджа с его другом и собратом по перу Вордсвортом. Даже у Вордсворта ему подчас не хватает той смелости и полета воображения, которые позволяют постичь суть явлений, его образы бывают слишком конкретны, погружены в ненужную детализацию. Кольридж определяет эту особенность словом «сухопрозаичность». Именно «сухо...», т.е. ему не хватает замутненности воды, которая смягчала бы режущий глаз конкретный, слишком четкий внешний облик предметов в излишних подробностях, отвлекающий от внутреннего смысла.

Таким образом, проблема соотношения образов воды и земли неразрывно связана с проблемой мимесиса, которую по-своему решает романтизм, настаивая на доминирующей роли фантазии, воображения, ассоциаций. 
Особенно остро встанет эта проблема в эпоху торжества реализма. Актуальным окажется вопрос, нужна или нет преломляющая призма, замутненная толща воды, или вода должна схлынуть, обнажив четкие очертания предметов, представленных во всех мельчайших подробностях и деталях, т.е. должна наступить, пользуясь определением Кольриджа, «сухопрозаичность»?

Переход к реализму: о т воды к земле

Трансформация диспозиции образов воды и земли в художественной культуре происходит в эпоху реализма. Новое направление - «искусство правды» (или «поэзия правды») как его нередко называли современники формируется в 30 40-е гг. XIX в. и в последующие десятилетия занимает магистральную линию в художественных процессах эпохи. Отвергнув отвлеченные романтические грезы и фантазии, оно опирается на материалистическое мировоззрение, научную картину мира, рационалистически выстроенные концепции общества и человека. Главным предметом художественного отражения становится человек, рассмотренный в контексте социального пространства.

В эпоху утверждения реализма с его интересом к социальному бытию человека «вода отступает». «Водные» образы иссякают. Суша, на которой в основном протекает жизнь социума, побеждает. В контексте общего материалистического устремления к познанию объективных законов реальности и позитивистского культа научного знания в образной системе преобладают устойчивость, конечность, определенность. Писатели и художники изучают человека в его повседневной жизни, в социальной среде. В его интерпретации проступают четкие рациональные критерии - социальный, а потом и биологический детерминизм (наследственность). Важные для романтиков иррациональные глубины сознания человека, порождающие его уникальность и созвучные природной стихии, на какое-то время остаются без внимания. Жанр пейзажа отступает. Художники часто обращаются к бытовому жанру.

Ключевым концептом в эстетике становится приоритет объективной реальности как внеположенной человеку объективной данности, которая становится главным предметом художественного отражении. Этому способствовали углубляющийся материализм в мировоззрении, «трезвомыслие» буржуазной эпохи, развитие научного мышления. Референции к реальности представлены в большинстве эстетических трактатов и манифестов (в работах Стендаля, Бальзака, Флобера, Дюранти, Шанфлери, Курбе, Гонкуров, 
Золя, Белинского, Чернышевского, Мохнацкого и др.) и в художественной практике.

При общей миметической устремленности не было четкого представления о правде жизни в искусстве. Прояснения и уточнения осуществлялись по мере обретения художественного опыта. И здесь были самые разные интерпретации в широком диапазоне - от концепции реалистического художественного синтеза жизненных явлений, при сохранении объективной логики жизни, до натуралистического подробного копирования действительности. Причем, эти эстетические позиции могли приближаться, перетекать, влиять друг на друга, что свидетельствует о сложной диалектике художественных исканий и творческом характере эпохи. В сущности, эти искания сосредоточились на проблеме мимесиса (хотя этот термин в XIX веке не был популярен и заменялся определениями - подражание, отражение, воспроизведение жизни).

Два крайних миметических полюса наметились еще в античности и представлены позициями Платона, который в мимесисе видел бессмысленное копирование вторичного «мира вещей», и Аристотеля, который интерпретировал мимесис как творческое воспроизведение действительности. При этом Аристотель допускает разные формы мимесиса: это может быть подражание «тому, как было и есть; или тому, как говорится и кажется; или тому, как должно быть» (1460b10) (Аристотель 1983, 676), т.е. жизни реальной, возможной и должной.

Эти проблемы стали актуальными в XIX столетии. В эстетике и художественной практике решался принципиальный методологический вопрос об отношении искусства к действительности, ответы на него предполагали разные модальности. Звучали разнообразные мнения о правде в художественнм произведения. «Я признаю только искренность в искусстве», - замечал один из первых теоретиков реализма Шанфлёри, а Флобер настаивал: «большое искусство должно быть научным и безличным» (Литературные манифесты французских реалистов 1935, 69, 16). Диккенс признавался, что «немного сгладил страшную действительность, разбавив ее, насколько мог, юмором» (Диккенс 1963, 43). Принцип реалистического синтеза раскрывал Мопассан: «Показывать правду - значит дать полную иллюзию правды, следуя обычной логике событий, а не копировать рабски хаотическое их чередование» (Памятники мировой эстетической мысли 1967, 662). В этом хоре позиций постепенно кристаллизовались представления о художественности (художественном синтезе) в реализме и о специфике реализма по отношению к натурализму. Реалистическая эстетика приходит к выводу: правдивые образы - это не простая копия жизни, но все-таки переосмысленный и по- 
особому синтезированный жизненный материал. В связи с этим актуальными становятся метафоры - оптическая призма, зеркало - прямое или выпуклое. Все они созвучны воде - как и вода, стекло может быть прозрачным или замутненным и давать различное преломление.

В понимании действительности искусство, стремившееся к правде, начинало все больше ориентироваться на научную картину мира. Под влиянием научно-технического прогресса и позитивистской философии появляется стремление сблизить задачи художника и ученого-естествоиспытателя это характерно для реализма, но особенно для натурализма. «Мы одновременно физиологи и поэты», - читаем в «Дневнике» Гонкуров (Гонкур 1964, 614). Э. Золя в «Экспериментальном романе» настаивает: «Романист - это и наблюдатель, и экспериментатор» (Памятники мировой эстетической мысли 1967, 701). Появляются жанры - «физиологический очерк», «экспериментальный роман».

Особое влияние оказывали именно естественные науки. Культуре XIX столетия удалось преодолеть механистический материализм и открыть органический уровень природы, на котором, собственно, и начинается жизнь она понималась теперь как более высокий и сложный уровень организации материи по отношению к уровню минеральному. Это было ключевое открытие, изменившее взгляд на природу, давшее мощный импульс развитию естественных наук (учения Ж. Б. Ламарка, Ж. Кювье, Сент-Илера, Ч. Дарвина, Г. Менделя, Л. Пастера). Увлечение биологическим организмом вызывало попытки экстраполировать на человека и общество законы органического мира, порождая неизбежный редукционизм в их интерпретации. Данная тенденция, позднее обозначенная Дж. Холдейном как «органицизм», проступала в позитивистской философии (О. Конт), социологии (Г. Спенсер), эстетике (И. Тэн). Проникала она и в художественное сознание эпохи, проявляясь в реалистическом и особенно натуралистическом искусстве. В художественных практиках использовались методы естественных наук: наблюдение, классификация, анализ, эксперимент. Социальная типизация выстраивалась по аналогии с типизацией животных, а социальный детерминизм - по аналогии с детерминизмом природным: «Общество подобно Природе. Ведь общество создает из человека, соответственно среде, где он действует, столько же разнообразных видов, сколько их существует в животном мире» (Бальзак 1951, 2-3).

Натура доминирует над творческим воображением, материя над духом, материальность, фактурность предметов становятся ощутимыми. Особенно ярко это проступает в творчестве Курбе. Гюстав Курбе - одна из самых репрезентативных фигур европейской реалистической живописи XIX века, 
первым организовал выставку с программным названием «Реализм» (1855). В его картинах - «Похороны в Орнане». «Дробильщики камня», «Веяльщицы», «Купальщицы», в пейзажах - проступает материальная весомость, «грубая зримость» формы. Это ощутимо даже в маринах. Зыбкая, неуловимая стихия становится тоже тяжеловесной, подчеркнуто материальной. Здесь вода - прежде всего, материя. В пейзаже «Скалы в Этрета» тяжелые волны набрасываются на скалистый берег - традиционный романтический сюжет, но ему дана новая интерпретация, на первом плане выделены скалы, что подчеркнуто в названии, - мощная, непобедимая, материя, твердая суша.

Это торжество материи, земли делает неактуальными в эпоху реализма морские пейзажи. Если же в поле художественного зрения попадает вода, то чаще это обозримый водоем (заводь, пруд, река); буйное колебание морских волн сменяет спокойная речная гладь - как тихие заводи на картинах «барбизонцев» (Т. Руссо, Ш. Добиньи, Ж. Дюпре, Н. Де ла Пенья).

В мощном устремлении к натуре могли быть крайности, приводившие к натурализму. Это эмпирическая стихия подробных, детализированных описаний (внешности персонажей, их одежды, обстановки, всей предметно-вещной среды, которая их окружает, деталей городского и природного ландшафта). Тенденция к добросовестной дотошности ощутима и в реалистической литературе XIX столетия, что делает ее подчас несколько тяжеловесной для современного искушенного читателя. В подробных, точных описаниях нет приблизительности, расплывчатости, текучести. Именно эта особенность «литературы правды» может быть в наибольшей степени называться «сухопрозаичностью», хотя собственно реализм, в отличие от натурализма, поднимается над описательностью и подчиняет ее емкому, полноценному художественному синтезу.

Кульминация торжества Земли, Материи - в романе Э. Золя «Земля», 15-м из серии «Ругон-Маккаров». Здесь представлена зримая, чувственно воспринимаемая материальность, плоть мира. Земля - средоточие материи, натуры. Возвращаются четкие границы, теперь в пейзажах отчетливо прочерчивается линия горизонта, «как чернильная черта, проведенная на бумаге» (Золя 1997, 17). Многие литературные образы земли у Золя напоминают живописные произведения близкого «барбизонцам» художника Ф. Милле, преданного теме крестьянского труда на земле («Анжелюс», «Сеятель», «Сборщицы колосьев» и др.). И в том, и в другом случае - высокие, четкие горизонты, огромный массив поля, занимающий большую часть пространства, серо-коричневая, земляная цветовая гамма

Теперь человек стоит перед подавляющим в своем величии пространством земли, твердой материи, которое сопоставимо с морским простором. 
Такое ощущение в романе Золя переживают крестьяне, приготовившиеся к работе в поле: «Окруженные со всех сторон беспредельной равниной, они стояли на краю участка, и лица их застыли в мечтательном раздумье, как у матросов, обреченных на одиночество среди бесконечного простора моря» (Золя 1997, 35). Земля в торжестве своей материальной мощи подавляет и восхищает так же, как бескрайнее море.

Заключени и

Таким образом, оппозиция образов воды и земли погружена в напряженный процесс главных эстетических исканий XIX столетия. Она связана с выражением иррационалистического художественного мышления романтиков, их натурфилософских и эстетических идей, а затем с поиском новой художественности, методологии художественного творчества в реализме. Опыт осмысления и освоения разных вариантов мимесиса в эпоху классического реализма XIX века оказался продуктивным для выживания реалистического искусства в современной художественной культуре, в его борьбе с модернизмом и сосуществовании с постмодернизмом. Актуальность проблемы проявляется в интересе к мимесису современной науки, спорах о нем вплоть до его отрицания (Барт 2009).

Эволюция образов воды и земли в художественной культуре XIX столетия не исчерпывается только ведущими направлениями - романтизмом и реализмом. Легкость волн, изменчивость и свобода водной стихии вернулись в импрессионизме, как только вновь были поколеблены рационалистические основы мировоззрения. Тот же вид в Этрета в пейзаже Клода Моне позволяет увидеть эти отличия. Импрессионистическая техника отдельных мазков разрушает четкие очертания, завершенность предметов, снимается тяжеловесность материи. Живописи импрессионистов созвучен поэтический призыв П. Верлена - «Почти бесплотность предпочти всему, что слишком плоть и тело».

Неоромантические тенденции, проступавшие с середины века, вновь возвращали уже знакомые «водные мотивы». На картине близкого «прерафаэлитам» Форда Брауна «Прощание с Англией» герои, отправляясь в далекое морское плавание, снова всматриваются вдаль, в неизвестность. Романтические образы перерастают в символы. Так, Офелия А. Рембо, плывущая по реке, воспринимается как символ хрупкой красоты, а река - как символ вечности («По сумрачной реке уже тысячелетье плывет Офелия, подобная цветку»). В образах-символах вновь просвечивают архетипы.

Интересно, что образы воды и земли не сосуществуют параллельно и равноправно, но как бы борются друг с другом, поочередно вытесняя друг друга. 
Сложные и динамичные мировоззренческие процессы, протекавшие в XIX столетии, отразились в актуализации или затихании тех или иных укорененных архетипов, что отразилось в образных системах литературы и искусства.

\section{Литература}

Аристотель 1983 - Аристотель. Сочинения. В 4 томах. АН СССР. Институт философии. Т. 4. Москва: Мысль, 645-680.

Бальзак 1951 - Оноре Бальзак. Собрание сочинений. В 15 томах. Пер. с франц. Т. 1. Москва: Государственное издательство художественной литературы.

Барт 2009 - Ролан Барт. S/Z. Пер с франц. 3-е изд. Москва: Академический Проект.

Берковский 2001 - Наум Яковлевич Берковский. Романтизм в Германии. СПб.: Азбука-классика.

Вайнштейн 1994 - Ольга Борисовна Вайнштейн. Язык романтической мысли. О философском стиле Новалиса и Фридриха Шлегеля / Российский государственный гуманитарный университет. Чтения по истории и теории культуры. Вып. 6. Историческая поэтика. Москва.

Гонкур 1964 - Эдмон Гонкур. Дневник. Записки о литературной жизни. Избранные страниubl. Пер. с франц. В 2 томах. Т. 1. Москва: Художественная литература.

Диккенс 1963 - Чарльз Диккенс. Полное собрание сочинений. В 30 томах. Т. 29. Москва: Художественная литература.

Дубова 2001 - Ольга Борисовна Дубова. Мимесис и пойэсис: Античная концепция «подражания» и зарождение европейской теории художественного творчества. Москва: Памятники исторической мысли.

Золя 1997 - Эмиль Золя. Собрание сочинений. В 12 томах. Т. 9. Москва: Художественная литература.

История искусств стран Западной Европы от Возрождения до начала XX века 2003 - История искусств стран Западной Европь от Возрождения до начала ХХ века. Искусство ХIX века. Кн. 1. СПб.: Дмитрий Буланин.

История искусств стран Западной Европы от Возрождения до начала XX века 2004 - История искусств стран Западной Европьь от Возрождения до начала ХХ века. Искусство ХIX века. Кн. 1. СПб.: Дмитрий Буланин.

Кольридж 1987 - Сэмюэл Кольридж. Избранные труды. История эстетики в памятниках и документах. Москва: Искусство, 39-185, 223-231.

Литературные манифесты французских реалистов 1935 - Литературные манифесты французских реалистов. Под редакцией и со вступительной статьей М. К. Клемана. Ленинград: Издательство писателей в Ленинграде.

Лёвит 2002 - Карл Лёвит. От Гегеля к Ницше. Революционный перелом в мышлении ХІХ века. СПб.: Владимир Даль.

Литературные манифесты западноевропейских романтиков 1980 - Литературные манифесты западноевропейских романтиков. Под ред. А. С. Дмитриева. Москва: Издательство Московского университета.

Mimesis in contemporary theory 1984 - Mimesis in contemporary theory: An interdisciplinary approach. Ed. By Mihai Spariosu. Philadelphia; Amsterdam; Benjamins. Culture ludens; Imitation a play in western culture. Vol. 1. The literary and philosophical debate. Ed. By Mihai Spariosu.

Мелетинский 2000 - Елиазар Моисеевич Мелетинский. Поэтика мифа. Москва: Наука.

Памятники мировой эстетической мысли 1967 - Памятники мировой эстетической мысли. В 5 томах. Т. 3. Эстетические учения Западной Европь и США (1789-1871). Москва: Искусство.

Платон 1971 - Платон. Сочинения в 3 томах. Изд. АН СССР. Институт философии. Философское наследие. Т. 3. Ч. 1. Москва: Мысль, 89-464. 
Подорога 2008 - Валерий Александрович Подорога. Мимесис. Материаль по аналитической антропологии литературе в двух томах. Т. 1. Н. Гоголь. Ф. Достоевский. Москва: Культурная революция. $688 \mathrm{c.}$

Прозерский 1983 - Вадим Викторович Прозерский. Позитивизм и эстетика. Ленинград: Издательство Ленинградского университета.

Ревалд 1994 - Джон Ревалд. История импрессионизма. Москва: Республика.

Фейербах 1995 - Людвиг Фейербах. Сочинения. В 2-х томах. Т. 1. Москва: Наука.

Французские стихи в переводе русских поэтов XIX-XX вв. 1973 - Французские стихи в переводе русских поэтов ХIX-XX вв. 2 изд. Москва: Прогресс, 488-489, 503-505.

Шеллинг 1987 - Ф. Шеллинг. Сочинения в 2 томах. Т. 1. Москва: Мысль, 1987.

Шеллинг 1989 - Ф. Шеллинг. Сочинения в 2 томах. Т. 2. Москва: Мысль, 1989.

\section{Elena Barnashova}

\section{THE OPPOSITION “WATER-LAND” IN THE EVOLUTION OF THE ARTISTIC CULTURE OF THE XIX CENTURY}

Summary

Well known established over many centuries and wandering in the culture of the archetypes associated with water. Water purification, dangerous nature, life, current time, and so on, many of them dating from ancient myths, folklore, entrenched as a universal, timeless images. In each epoch of the updated water archetypes, reflecting the deep intentions of the culture of his time. In the nineteenth century, which marked a painful and blast crisis of rationalism, we can distinguish archetype: water as the embodiment irrational - and as such it is opposed to the earth as the embodiment of rational, orderly. Accordingly, the antithesis of "rational-irrational" appears in literature and art through the contrast of images of earth and water. This binary reveals itself in the evolution of the leading art schools of romanticism and realism.

"Water" images are among the most popular in romanticism, allowed to implement its leading artistic and aesthetic ideas. Irrational element, the unpredictability, the wrongness of destiny embodied in the images of a stormy sea, repetitive plot: caught in a storm, the ship is torn among the waves (the scene of the shipwreck of don Juan Byron, dramatic seascapes U. Turner, "the Raft of the Medusa" So Gericault). The motif of loneliness appeared in the image of the lost at sea "lone sails". The feeling of infinity being transmitted by way of water (mostly marine) space. In the works of the romantics often appears the image of a person standing on the shore, staring out to sea (K. D. Frederick). Beach (flat rock) is land's end, the meeting of land and water, sustainable and fragile, finite and infinite, the rational and the irrational. Images of the sea reflect the concept of nature in romanticism, which is understood as a free, infinite, irrational ele- 
ment, as opposed to the outdated, rationalistic culture of classicism. In romantic natural philosophy nature was inspired and attuned to the mental States of man (F. Schelling, F. Schlegel, Novalis, S. Coleridge). Favorite romantic genre of landscape is, as a rule, the landscape of the human soul.

In the era of approval of realism with his interest in social existence of man, "the water recedes". "Water" images runs out. Drying, which occurs mainly social Genesis, wins. In the context of the General materialistic aspirations to knowledge of objective laws of reality and positivist cult of scientific knowledge in the image system is dominated by the resistance, finiteness, definiteness. Writers study of man in his everyday life, in social settings, interpreting it in terms of social and biological determinism. Artists often approach to genre. In reality the art of seeking the truth, more and more focused on the scientific picture of the world. Under the influence of scientific-technical progress and positivist philosophy aspires to bring together the tasks of the artist and the scientist. Aesthetics solves the question of the relation of art to reality, and offers a different understanding of truth in art. Acute problem of artistic synthesis. Realism comes to the recognition of the need of refraction life experiences through the prism of the author's perception. This makes the actual often-used metaphor - optic prism, mirror - straight or convex. They are all consonant with water - as water glass can be transparent or opaque and give different refraction.

Nature dominates the creative imagination, matter over mind, materiality, texture objects become tangible. The triumph of matter, the earth makes irrelevant seascapes. If the field of view enters the water, it is foreseeable water (pool, pond, river), a violent oscillation of the waves was replaced by calm water as a quiet backwater on the paintings "Barbizon painters". Meet and seascapes, for example, "the Cliffs at Etretat", Courbet, but the traditional romantic story the onslaught of waves on coastal cliffs - appears in a new interpretation. This onslaught is not free water, but matter itself, the hardness of rocks, land, tangible materiality of the waves. Water is also a weighty, heavy, as land. The culmination of the celebration of the Earth, Matter - in the novel E. Zola "Earth". The image of the earth is visible, sensible materiality, the flesh of the world.

Easy waves, variability and freedom of water returned to the impressionism, once again shaken rationalistic philosophy.

Interestingly, the images of water and land do not exist in parallel and equal, but seem to be fighting with each other, alternately displacing each other. Complex and dynamic ideological processes that took place in the nineteenth century, reflected in the actualization or the remission of those or other rooted archetypes, which is reflected in grid systems literature and art. 